\title{
SISTEM APLIKASI PEMESANAN CATERING PADA IBU HOLIPAH
}

\author{
Akbar Kurniawan', Rahnita Nuzulah' ${ }^{2}$, Aswin Saputra ${ }^{3}$ \\ Program Studi Teknik Informatika, Fakultas Teknik dan Ilmu Komputer, \\ Universitas Indraprasta PGRI \\ Jalan Raya Tengah No 80, Kelurahan Gedong, Pasar Rebo, Jakarta Timur \\ kurniawanakbar0@gmail.com ${ }^{1}$, rahnita21@gmail.com², saputraaswin133@gmail.com ${ }^{3}$
}

\begin{abstract}
Abstrak
Teknologi Informasi berkembang sangat cepat belakangan ini. Selaras dengan hal itu, kebutuhan manusia pun semakin berkembang baik untuk kebutuhan pribadi maupun untuk keperluan peningkatan usaha. Bisnis catering pada umumnya adalah bisnis lokal yang melayani hanya pasar lokal yang masih bisa dengan mudah dijangkau melalui angkutan darat. Sistem order secara manual pada suatu industri food beverage dapat menimbulkan beberapa masalah. Catering Ibu Holipah mengalami masalah yang sering dihadapi yaitu ketika konsumen sudah memutuskan menu makanan dan minuman yang ingin dipesan, pembeli harus menunggu pelayan dalam mencatat pesanan atau mengambil daftar pesanan yang telah ditulis. Dengan demikian, dibuat sebuah aplikasi yang mewadahi pengelola catering Ibu Holipah dan konsumen untuk melakukan pemesanan lebih cepat. Dengan terciptanya sistem aplikasi tersebut, catering Ibu Holipah bisa melakukan tindakan yang efisien untuk pemesanan dari konsumen. Dengan adanya sistem aplikasi yang berbasis Java dan Netbeans dapat menggantikan beberapa sistem manual menjadi sistem terkomputerisasi untuk pengumpulan data dan pembuatan laporan yang lebih efektif dan efisien terhadap catering Ibu Holipah.
\end{abstract}

Kata Kunci: Pemesanan, Catering, Java, Netbeans

\begin{abstract}
Information technology is growing very fast these days. In line with that, human needs are growing both for personal needs and for business improvement purposes. Catering business in general is a local business that serves only the local market that can still be easily reached by land transportation. Manually ordering systems in the food beverage industry can cause some problems. Catering Ms. Holipah has a problem that is often faced, namely when consumers have decided on the menu of food and drinks that want to be ordered, buyers must wait for the waiter to record the order or take a list of orders that have been written. Thus, an application was created that accommodates catering managers Of Holipah and consumers to make orders faster. With the creation of the application system, Catering Ms. Holipah can do an efficient for ordering from consumers. Java and Netbeans-based application systems can replace some manual systems into computerized systems for data collection and report creation that is more effective and efficient against catering.
\end{abstract}

Keywords: Ordering, Catering, Java, Netbeans

\section{PENDAHULUAN}

Teknologi Informasi berkembang sangat cepat belakangan ini. Selaras dengan hal itu, kebutuhan manusiapun semakin berkembang baik untuk kebutuhan pribadi maupun untuk keperluan peningkatan usaha. Bisnis catering pada umumnya adalah bisnis lokal yang melayani hanya pasar lokal yang masih bisa dengan mudah dijangkau melalui angkutan darat. Hal ini dikarenakan sifat dari bisnis catering yang membutuhkan persiapan yang sangat intensif sebelum acara yang dilayani berlangsung. Sistem order secara manual pada suatu industri food beverage dapat menimbulkan beberapa masalah. Masalah yang sering dihadapi adalah ketika konsumen sudah memutuskan menu makanan dan minuman yang ingin dipesan, pembeli harus menunggu lama kedatangan pelayan untuk mencatat pesanan atau mengambil daftar pesanan yang telah ditulis. Hal ini dikarenakan keterbatasan pelayan atau pada saat itu pelayan juga sedang melayani konsumen lainnya. Keterlambatan pencatatan pesanan tentu dapat menyebabkan keterlambatan penyediaan menu yang telah dipesan, sehingga konsumen harus menunggu lama. Catering Ibu Holipah masih menggunakan sistem operasional manual dengan sistem yang cukup sederhana seperti cara membuat pesanan, pembayaran, sampai 
membuat laporan hasil transaksi. Sehingga tidak efektif dan mudah hilangnya data. Oleh karena itu peneliti tertarik untuk membuat aplikasi pemesanan catering berbasis java yang akan memudahkan dalam dalam pencatatan dan pembuatan laporan. Perancangan (Design) adalah tahap pembuatan spesifikasi mengenai arsitektur program, gaya, tampilan dan kebutuhan material atau bahan untuk program (Binanto, 2010). Bahasa pemrograman java merupakan salah satu dari sekian banyak bahasa pemograman yang dapat dijalankan di berbagai sistem operasi termasuk telepon genggam (Nofriadi, 2016).

\section{PENELITIAN RELEVAN}

Sistem aplikasi mampu meningkatkan omset penjualan, meningkat kualitas produk yang dihasilkan meningkatkan keahlian dan sumber daya manusia dari para anggota kelompok usaha, serta dapat menerapkan teknologi informasi (Hayat, 2017). Sebuah aplikasi pemesanan catering berbasis mobile android dapat membantu dalam proses pemesanan catering oleh pelangan serta pengelolaan data pemesanan catering (Syani \& Werstantia, 2018). Sistem informasi pemesanan menu makanan dan minuman berbasis web ini dapat membantu proses pemesanan pada salah satu kafe Made in Bandung (Caniati, et al., 2017). Sistem pemesanan yang terkomputerisasi lebih efektif dan efisien serta sistem pemesanan makanan dan minuman dibandingkan dengan sistem yang terdahulu (Maryanto \& Kesuma, 2017). Dalam mewujudkan kepuasan konsumen dalam pemesanan makanan, dibuat sebuah rancang bangun sistem informasi pemesanan pemesanan makanan berbasis web dengan menggunakan PHP dan Mysql (Saputri, et al., 2019).

\section{METODE PENELITIAN}

Desain peneletian menggunakan Metode penelitian yang digunakan peneliti adalah metode grounded (grounded research), yaitu suatu metode penelitian berdasarkan pada fakta dan menggunakan analisis perbandingan dengan tujuan mengadakan pengamatan, menetapkan konsep, membuktikan teori, mengembangkan teori, pengumpulan data dan analisis data dalam waktu yang bersamaan (Sugiyono, 2014). Metode grounded (grounded research) bertujuan unutk mengetahui proses pengarsipan yang dilakukan selama ini. Dengan metode ini diharapkan dapat mengetahui perbandingan antara data/ fakta di lapangan dengan teori-teori yang ada terhadap proses yang ada sehingga mempermudah peneliti dalam membuat rencangan sistem pengarsipan bagi perusahaan. Metode yang penelitian digunakan untuk pengumpulan data dalam penelitian kepustakaan (library research), penelitian lapangan (field research), dan wawancara. Berikut penjelasan dari metode - metode tersebut:

1. Pengamatan langsung (observation)

Pengertian observasi ialah metode atau cara - cara yang menganalisis dan mengadakan pencatatan secara sistematis mengenai tingkah laku dengan melihat dan mengamati individual secara langsung.

2. Wawancara (Interview)

Wawancara merupakan proses memperoleh keterangan untuk tujuan penelitian dengan cara tanya jawab sambil bertatap muka. Peneliti melakukan tanya jawab langsung kepada pekerja di catering Ibu Holipah. Yang berkaitan dengan masalah yang akan dipecahkan sehingga peneliti memperoleh data yang akurat.

3. Dokumantasi (Documentation)

Penelitian melakukan pengumpulan data dengan cara melihat dan mencatat data yang ada pada dokumen atau arsip pada catering Ibu Holipah.

\section{HASIL DAN PEMBAHASAN}

Aturan bisnis sistem yang diusulkan oleh peneliti, agar sistem informasi lebih cepat, tepat dan akurat antara lain sebagai berikut:

1. Pelanggan memberikan data diri kepada admin untuk didata dan disimpan di database, 
2. Admin memberikan rekapitulasi Pelanggan dan memberikan info registrasi ke pemilik toko untuk diolah sebagai data.

3. Admin membuat laporan berkas pelanggan, sedangkan Admin membuat laporan pelanggan untuk dilaporkan kepada pemilik.

Berikut ini merupakan penggambaran tentang sistem pada Aplikasi Sistem Pemesanan catering yang Diusulkan:

\section{Dekomposisi Sistem yang Diusulkan}

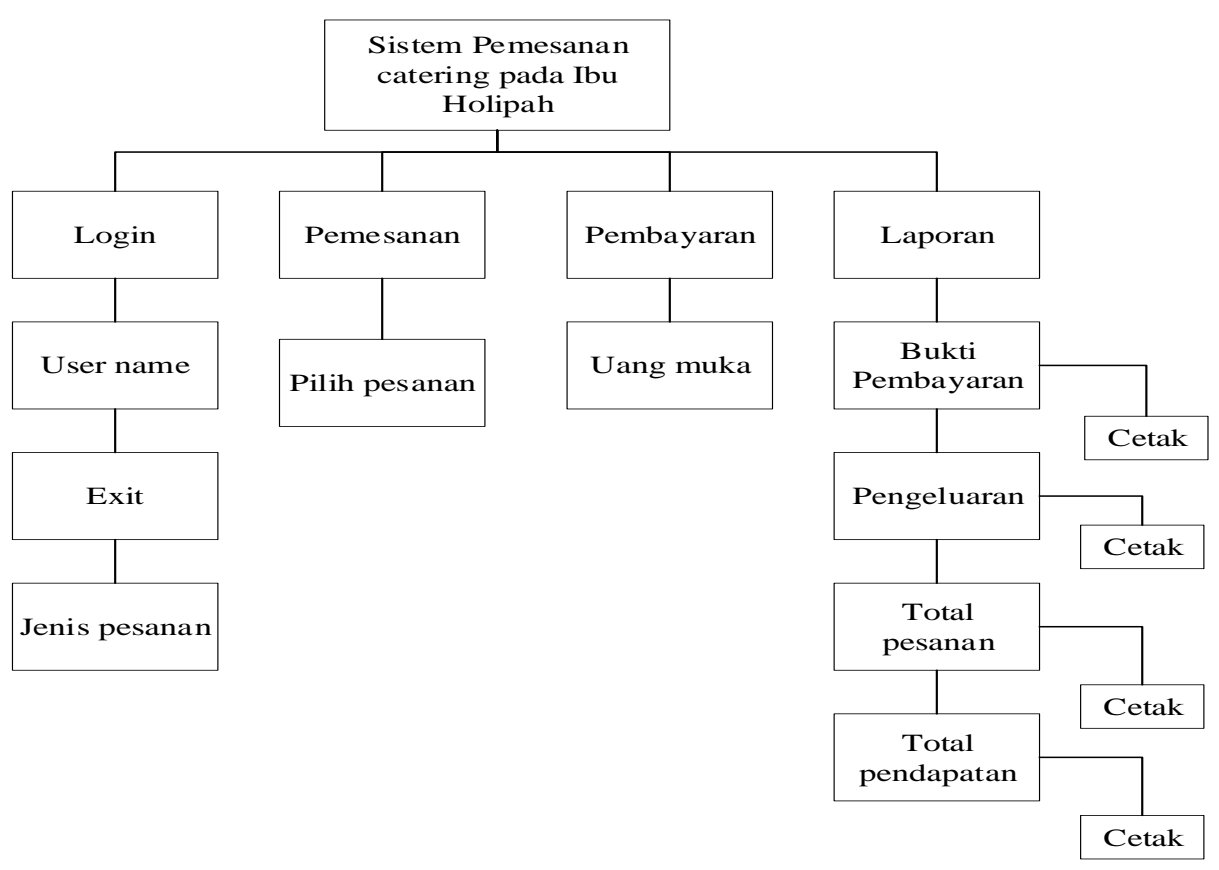

Gambar 1. Dekomoposisi Fungsi Sistem

\section{Diagram Konteks Yang Diusulkan}

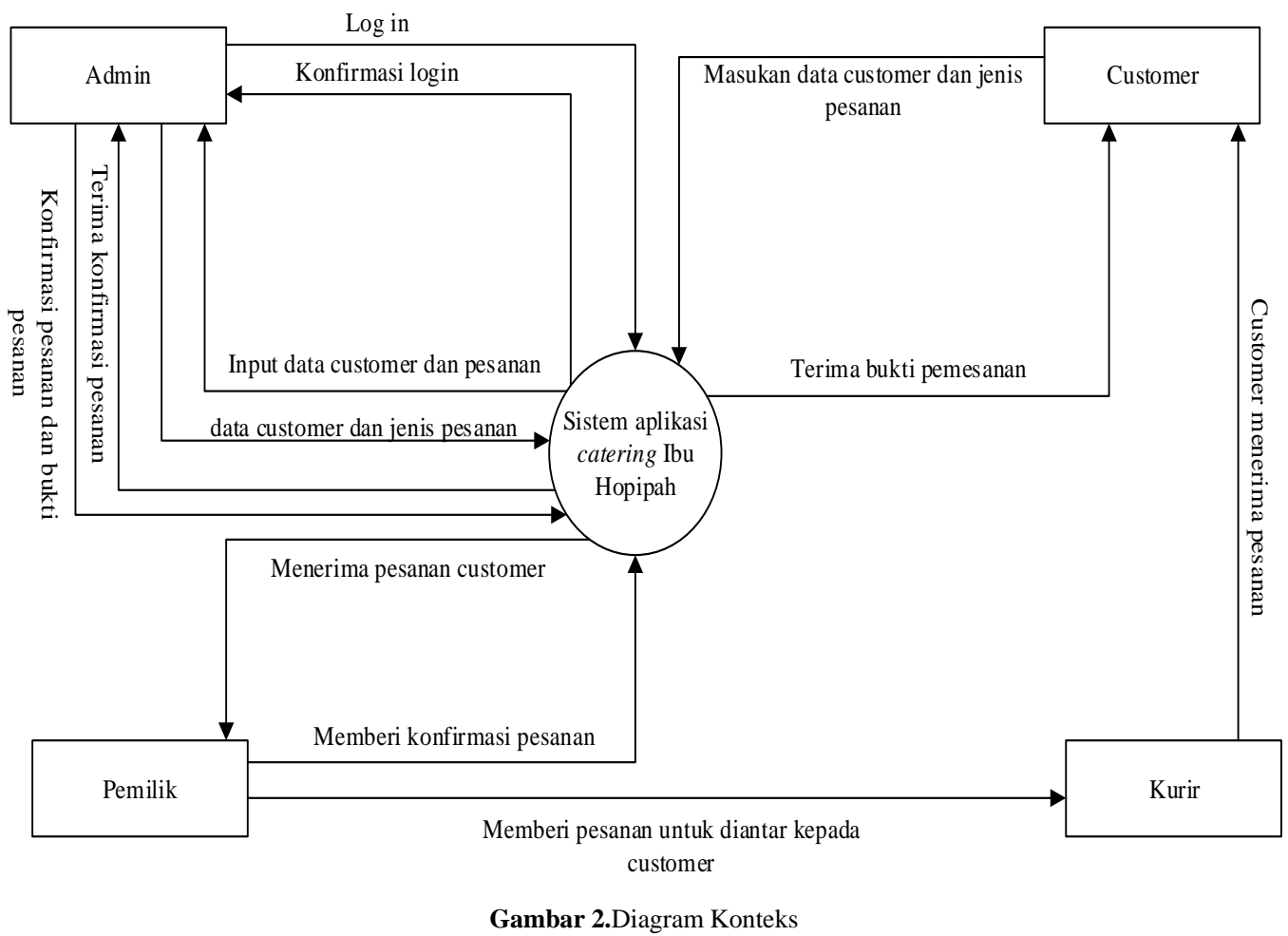


Jurnal Riset dan Aplikasi Mahasiswa Informatika (JRAMI)

Vol Q2 No 04 Tahun ZQZI

e-ISSN : $2715-8756$

\section{Struktur Data Yang Diusulkan}

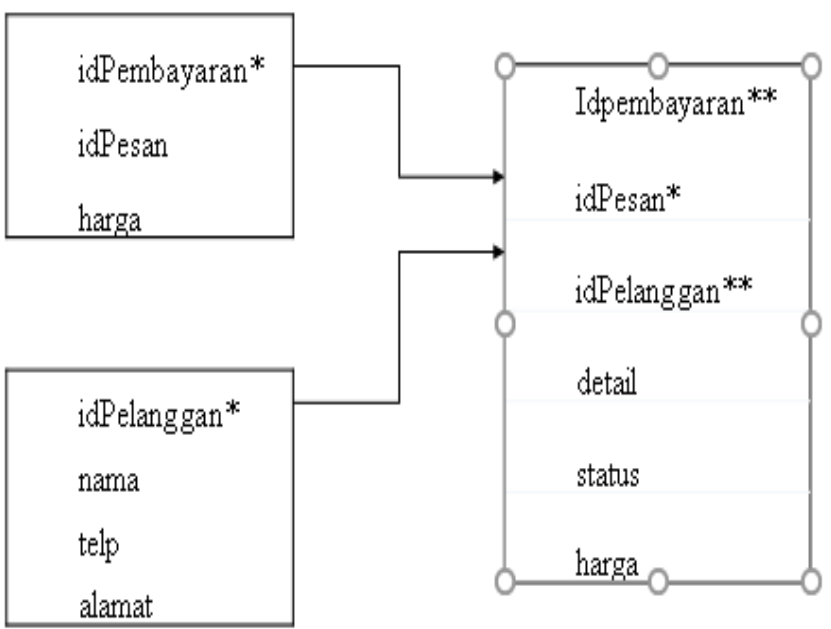

\section{Entity Relationship Diagram}

Gambar 3. Struktur dan Relasi Database

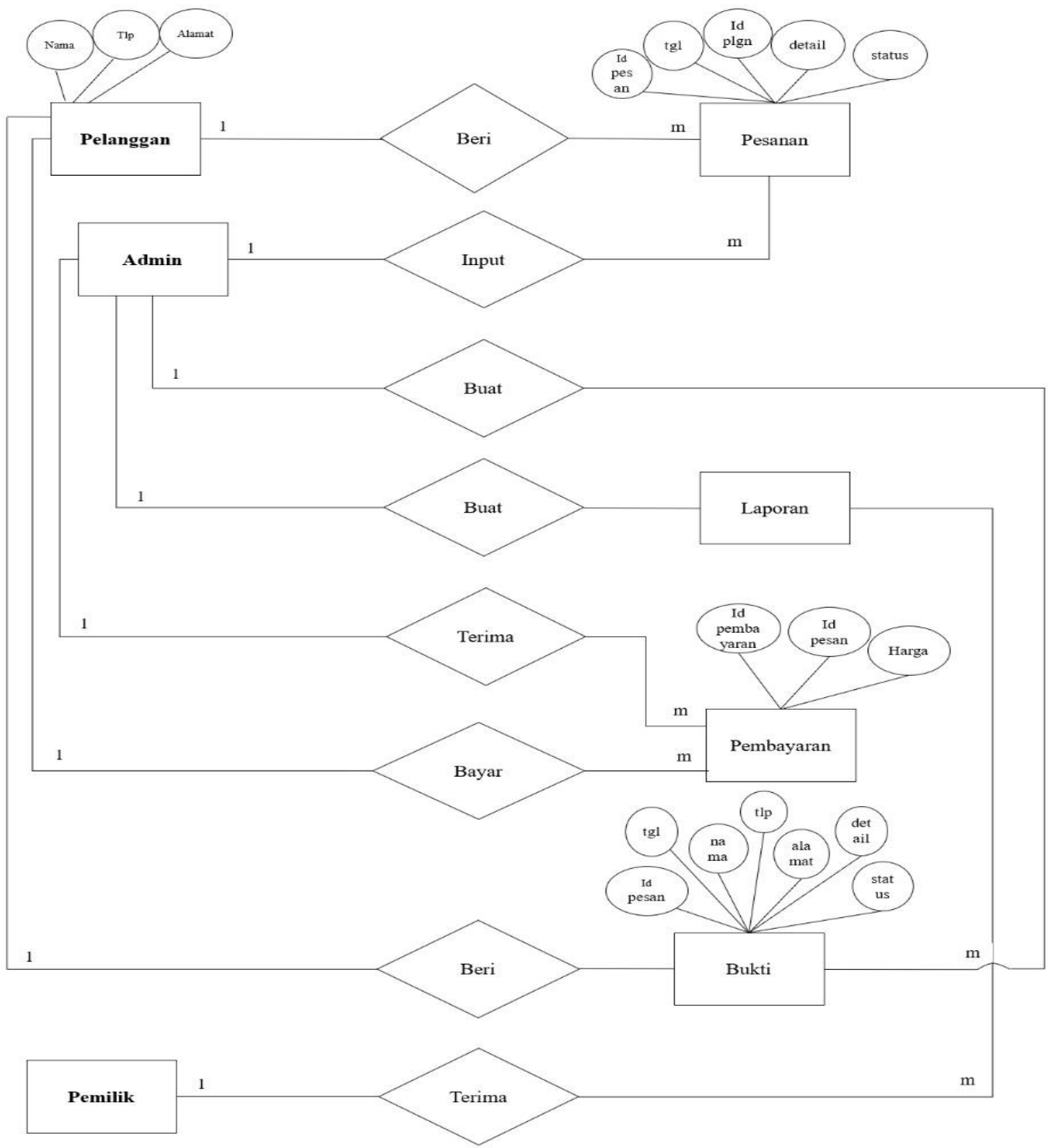

Gambar 4. Entity Relationship Diagram 


\section{Tampilan Layar}

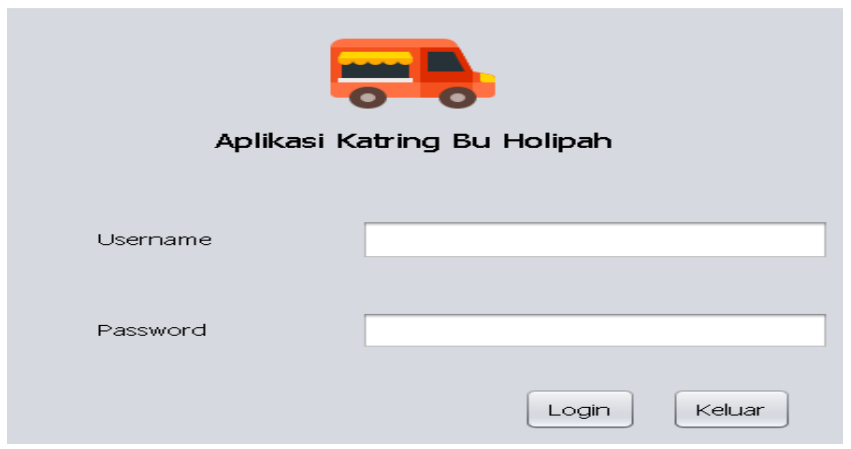

Gambar 5. Tampilan Menu Login

Tampilan layer di atas merupakan form login digunakan untuk memberikan akses kepada admin untuk masuk ke dalam sistem.

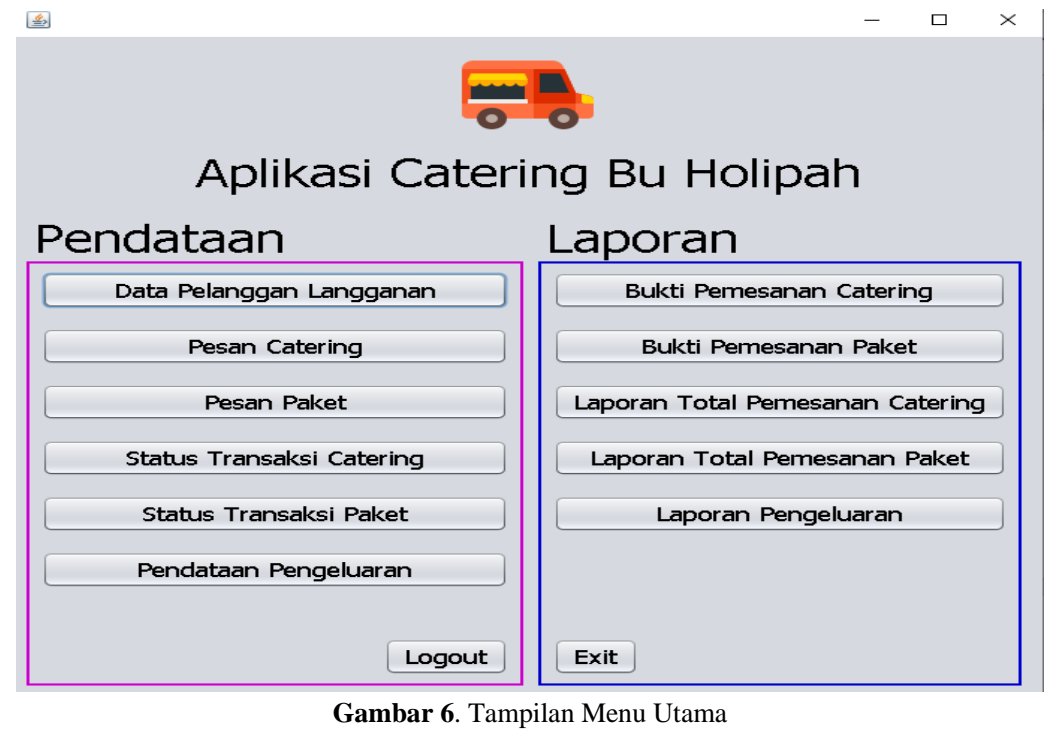

Layar diatas menampilkan menu utama pada aplikasi pemesanan catering. Pada layar utama tersedia berbagai menu yang dapat digunakan seperti pendataan pelanggan langganan, pesanan catering, pesan paket, status transaksi catering, status transaksi paket, pendataan pengeluaran dan laporan yang berfungsi untuk mencetak dokumen-dokumen yang berkaitan dengan laporan pada aplikasi.

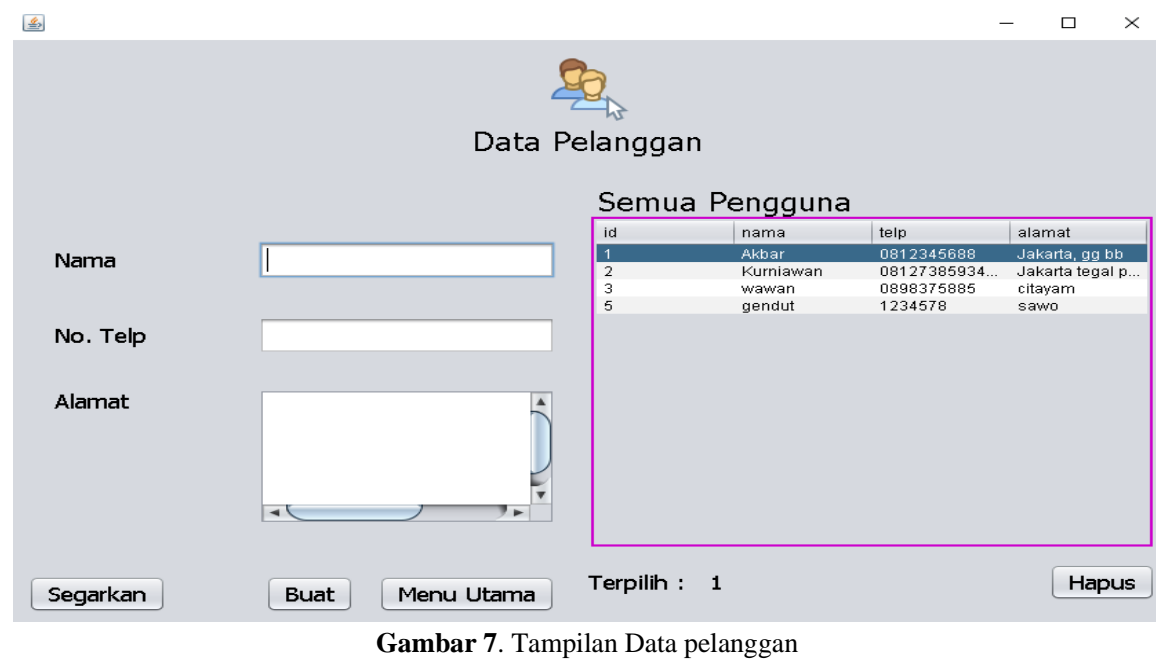


Layar di atas menampilkan menu data pelanggan dan terdapat menu pelanggan yang sudah berlangganan pada catering Ibu Holipah, untuk memulainya proses pemesanan. Bagi pelanggan baru akan diinput nama, nomor telepon, dan alamat untuk validasi data.

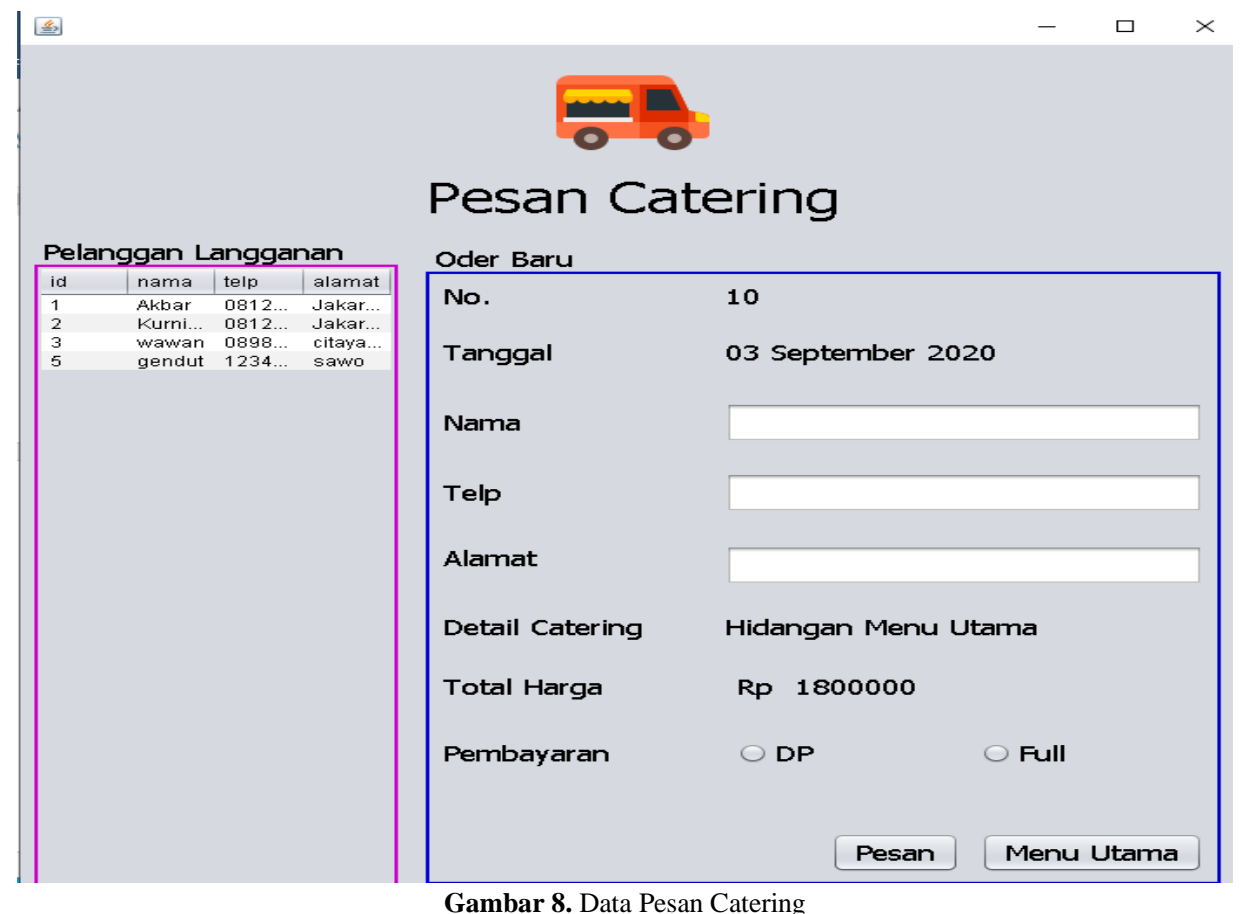

Layar di atas tersedia data-data yang harus di isi oleh admin dari data pemesan seperti nama, nomor telepon, alamat, dan metode pembayaran. Pesanan catering itu adalah makanan yang hanya mempunyai 1 paket berupa prasmanan seperti acara pernikahan.

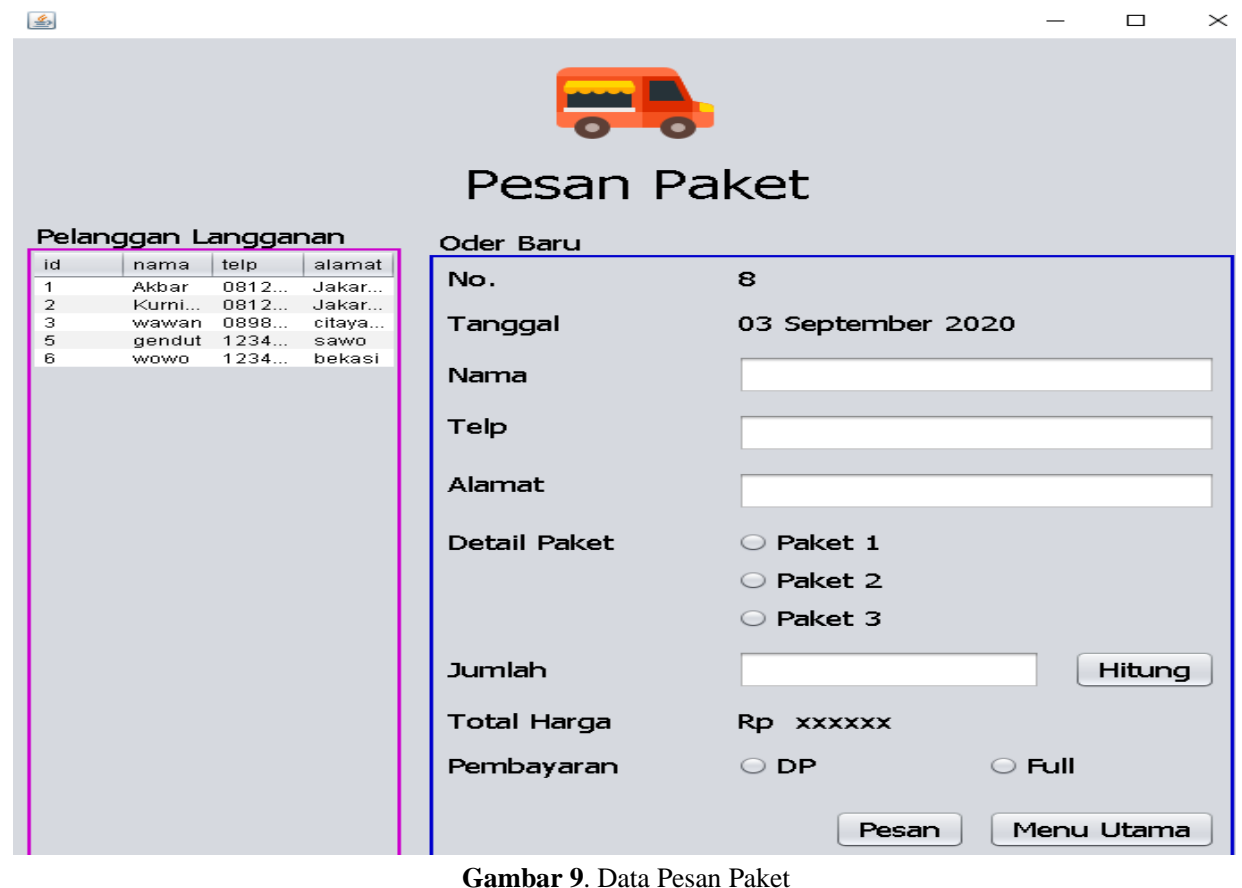

Layar di atas menampilkan data pesan paket, sama seperti data pesanan catering. Perbedaannya terletak pada harga dan menu makanan yang membedakan data pesan paket dengan data pesan catering. 


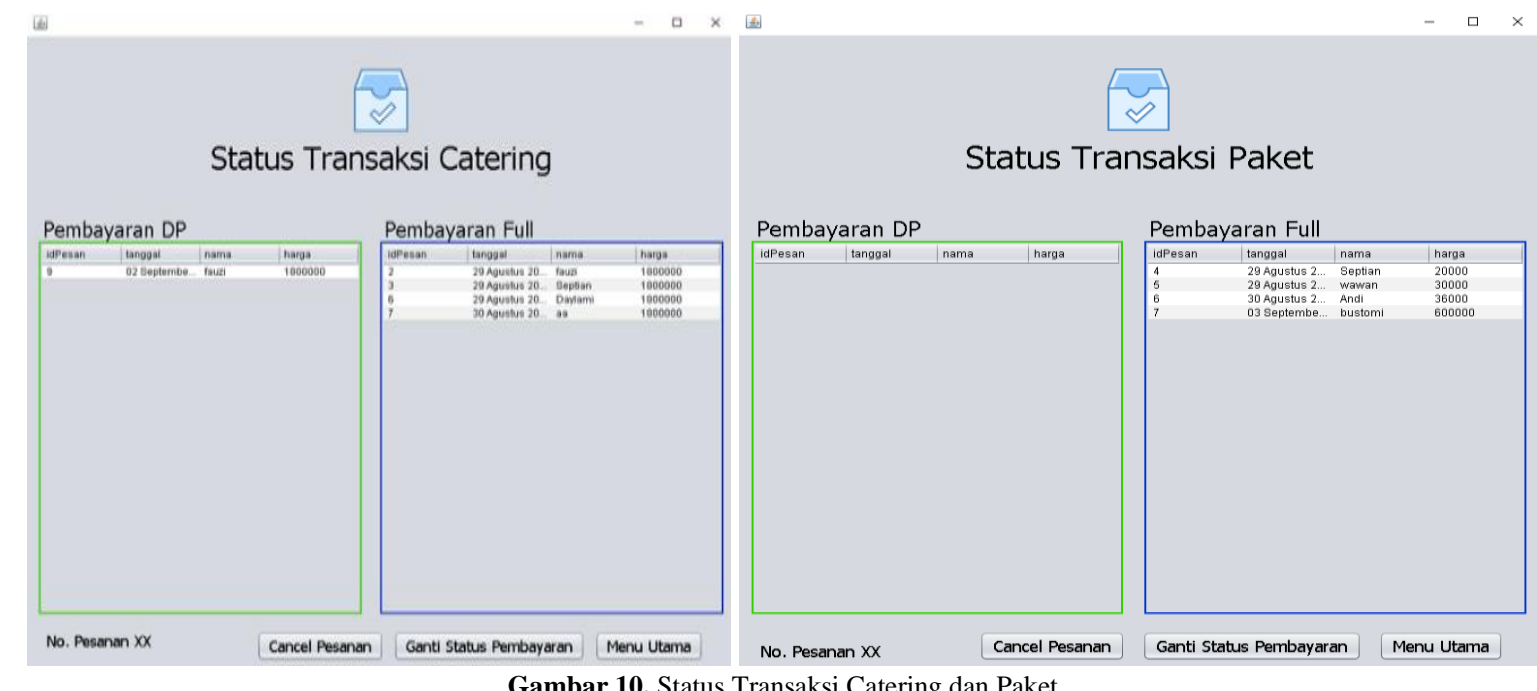

Pada Layar di atas menjelaskan tentang status transaksi pada pesanan catering dan paket. Status transaksi ini dapat diubah untuk metode pembayaran, dimana pembayaran Down Payment (DP) bisa diubah menjadi pembayaran full.

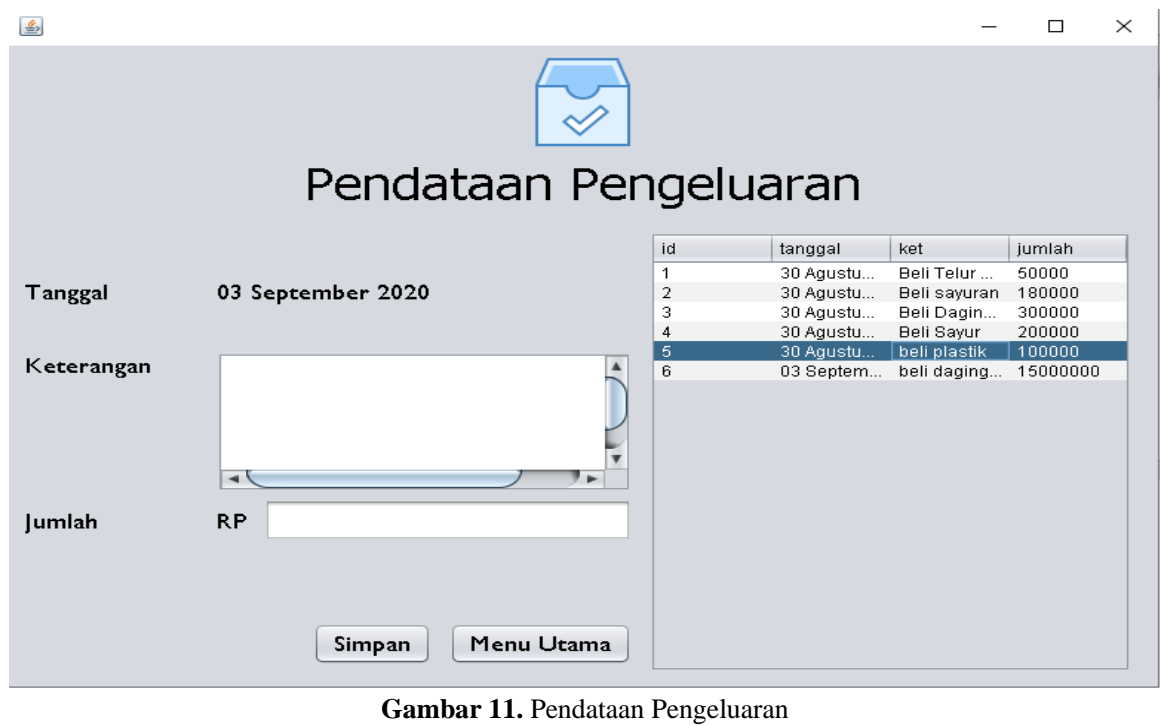

Pada layar di atas menjelaskan mengenai data pengeluaran catering Ibu Holipah setiap bulan agar lebih mudah untuk dimonitor dan tidak perlu lagi menggunakan buku/kertas untuk mendata pengeluaran yang telah dilakukan.

\section{SIMPULAN}

Berdasarkan hasil pembahasan yang telah diuraikan pada bab - bab sebelumnya, maka peneliti dapat menarik kesimpulan yaitu dihasilkan sebuah aplikasi yang didalamnya mewadahi pengelola catering Ibu Holipah dan pelanggan untuk melakukan pemesanan lebih cepat. Dengan terciptanya sistem aplikasi tersebut, catering Ibu Holipah bisa melakukan tindakan yang efisien untuk pemesanan dari costumer. Dengan adanya sistem splikasi ini dapat menggantikan beberapa sistem manual menjadi sistem terkomputerisasi untuk pengumpulan data dan pembuatan laporan yang lebih efektif dan efisien terhadap catering Ibu Holipah. Sistem aplikasi pemesanan dan pelaporan data ini diharapkan dapat meningkatkan kualitas dan kecepatan kerja pada catering Ibu Holipah agar mampu bersaing dengan usaha sejenis. 


\section{DAFTAR PUSTAKA}

Binanto, Iwan. (2010). Multimedia Digital - Dasar Teori dan Pengembangannya. Yogyakarta: Andi Publisher.

Caniati, N., Ghozal, A. L. \& Sumarudin, A., 2017. Implementasi Sistem Informasi Pemesanan Menu Makanan Dan Minuman Pada Kafe Berbasis Web Menggunaka Jaringan Internet. Jurnal Ilmiah Ilmu Komputer, 3(2), pp. 8-13.

Hayat, C., 2017. IbM Industri Rumah Tangga Makanan Tradisional Pada Kelompok Usaha Di Wonosobo. UNES Journal of Community Service, 2(2), pp. 118-126.

Maryanto, A. \& Kesuma, C., 2017. Sistem Informasi Pemesanan Makanan Dan Minuman Berbasis Web Pada Rumah Makan Gazebo Purwokerto. Indonesian Journal on Networking and Security, 6(4), pp. 1-8.

Nofriadi. (2015). Java Fundamental dengan Netbeans 8.0.2. Yogyakarta: DeepublishSaputri, Z. R., Oktavia, A. N., Ramdhani, L. S. \& Suherman, A., 2019. Rancang Bangun Sistem Informasi Pemesanan Makanan Berbasis Web Pada Cafe Surabiku. Jurnal Teknologi dan Informasi, 9(1), pp. 66-77.

Sugiyono, 2014. Metode Penelitian Pendidikan Pendekatan Kuantitatif, Kualitatif, dan R\&D. Bandung: Alfabeta.

Syani, M. \& Werstantia, N., 2018. Perancangan Aplikasi Pemesanan Catering Berbasis Mobile Android. Jurnal Ilmiah Ilmu dan Teknologi Rekayasa, 2(1), pp. 109-117. 